\title{
Pemphigus Vulgaris and Bullous Pemphigoid: Update on Diagnosis and Treatment
}

\author{
Vito Di Lernia, ${ }^{1}$ Dahiana M. Casanova, ${ }^{1}$ Mohamad Goldust,${ }^{2}$ Cinzia Ricci ${ }^{1}$
}

1 Dermatology Unit, Arcispedale Santa Maria Nuova, Azienda USL-IRCCS di Reggio Emilia, Italy

2 University Guglielmo Marconi, Rome, Italy \& Department of Dermatology, University Hospital, Basel, Switzerland

Key words: pemphigus, pemphigoid, autoimmune, bullous, disorder

Citation: Di Lernia V, Casanova DM, Goldust M, Ricci C. Pemphigus vulgaris and bullous pemphigoid: update on diagnosis and treatment. Dermatol Pract Concept. 2020;10(3):e2020050. DOI: https://doi.org/10.5826/dpc.1003a50

Accepted: March 5, 2020; Published: June 29, 2020

Copyright: $\odot 2020$ Di Lernia et al. This is an open-access article distributed under the terms of the Creative Commons Attribution License, which permits unrestricted use, distribution, and reproduction in any medium, provided the original author and source are credited.

Funding: None.

Competing interests: The authors have no conflicts of interest to disclose.

Authorship: All authors have contributed significantly to this publication.

Corresponding author: Vito Di Lernia, MD, Dermatology Unit, Arcispedale Santa Maria Nuova, viale Risorgimento 80, 42123 Reggio Emilia, Italy. Email: vito.dilernia@ausl.re.it

ABSTRACT Autoimmune bullous disorders are a heterogeneous spectrum of skin disorders characterized by the production of autoantibodies against adhesion molecules of the skin. The 2 major groups of diseases are "pemphigus diseases" and "autoimmune bullous diseases of the pemphigoid type." Pemphigus diseases are a group of autoimmune blistering diseases of the skin and mucous membranes characterized by intraepithelial cleft and acantholysis. The main subtypes of pemphigus include pemphigus vulgaris, pemphigus foliaceus, and paraneoplastic pemphigus. Diagnosis is based on clinical manifestations and confirmed with histological, immunofluorescence, and serological testing. Recently multivariant enzyme-linked immunosorbent assay systems have been developed as practical screening tools for patients with suspected autoimmune bullous dermatoses. The current first-line treatment of pemphigus is based on systemic corticosteroids that are often combined with immunosuppressive adjuvants, such as azathioprine, mycophenolate mofetil, and the anti-CD20 monoclonal antibody rituximab, usually at initiation of treatment. Rituximab efficacy is higher when it is administered early in the course of the disease. Therefore, it should be used as first-line treatment to improve efficacy and reduce cumulative doses of corticosteroids and their side effects. Treatment of bullous pemphigoid is based on disease extension. Localized and mild forms can be treated with superpotent topical corticosteroids or with nonimmunosuppressive agents. In patients with generalized disease or whose disease is resistant to the treatments described above, systemic corticosteroids are preferred and effective. Adjuvant immunosuppressants are often combined with steroids for their steroid-sparing effect.

\section{Introduction}

Autoimmune bullous disorders (ABDs) encompass a number of heterogeneous conditions linked by the loss of tolerance to structural proteins of the skin. As a consequence of breakdown of tolerance, autoantibodies targeting epi- dermal or subepidermal adhesion proteins are produced. The loss of adhesion between keratinocytes or between basal keratinocytes and the underlying epidermal basement membrane leads to an impaired resilience of the epidermis resulting in intraepithelial or subepithelial blisters and erosions of the skin and mucous membranes. ABDs 
Table 1. Classification of Pemphigus

\begin{tabular}{|l|l|}
\hline \multicolumn{1}{|c|}{ Type } & \multicolumn{1}{c|}{ Variants } \\
\hline Pemphigus vulgaris & $\begin{array}{l}\text { Pemphigus vegetans } \\
\text { Pemphigus herpetiformis }\end{array}$ \\
\hline Pemphigus foliaceus & $\begin{array}{l}\text { Fogo selvagem (pemphigus } \\
\text { brasiliensis) } \\
\text { Pemphigus erythematosus }\end{array}$ \\
\hline $\begin{array}{l}\text { Paraneoplastic } \\
\text { pemphigus }\end{array}$ & \\
\hline Atypical pemphigus & \\
\hline $\begin{array}{l}\text { "Drug-induced" } \\
\text { pemphigus }\end{array}$ & \\
\hline IgA pemphigus & \\
\hline
\end{tabular}

Ig = immunoglobulin.

are a major cause of severe morbidity and considerable mortality [1].

Based on the available literature data, this paper aims to provide an up-to-date overview on diagnosis and therapy of pemphigus vulgaris (PV) and bullous pemphigoid (BP), which represent the 2 major diseases in the heterogeneous clinical spectrum of ABDs.

\section{Classification}

The classification of an ABD relies on the level of blistering and considers 2 major groups of diseases, namely "pemphigus diseases"(PDs) and "ABDs of the pemphigoid type."

PDs are characterized by the production of pathogenic autoantibodies directed against different proteins of the desmosome, leading histologically to intraepithelial blistering. There are several variants of pemphigus, but the 3 major forms include PV, pemphigus foliaceus (PF), and paraneoplas- tic pemphigus (Table 1). Pemphigus is driven by pathogenic antibodies to both desmoglein (Dsg) 1 and 3 (PV, mucocutaneous type), or Dsg3 (PV, mucosal dominant-type), or Dsg1 $(\mathrm{PF})$. Numerous antigens are involved in paraneoplastic pemphigus (Table 2).

ABDs of the pemphigoid type or autoimmune subepidermal blistering diseases of the skin and mucosae constitute a large group of diseases characterized by the production of circulating autoantibodies against several structural proteins of the basement membrane zone, leading histologically to subepidermal blistering. The main disorders include BP, pemphigoid gestationis, mucous membrane pemphigoid, epidermolysis bullosa acquisita, and anti-p200 pemphigoid [2] (Table 3). BP is characterized by the generation of autoantibodies directed in particular against BP180/collagen XVII and BP230/dystonin.

\section{Epidemiology}

Prospective studies suggest the incidence rates of ABDs are in the range of 14.5-20.4/million [3-5]. Most of the available epidemiological data derive from PV, the most frequently reported disorder among the PDs, and BP [3].

PV incidence appears to be highly variable according to geographic regions and ethnic groups. The incidence rates reported in European prospective studies range between 0.5 and $4.0 /$ million [5,6]. Higher rates, up to $16.1 /$ million/year, have been observed in subjects from Israel and Iran [7,8]. In fact, the disease is more common among individuals of Ashkenazi origin, but also in ethnic groups from Iraq and Iran. Therefore, ethnic differences should be taken into account when comparing incidence rates in countries with populations of Jewish heritage [3,9]. Pemphigus is most frequently diagnosed between ages 50 and 60 in European countries, but it can be seen earlier outside of Europe.

Table 2. Classification and Autoantigens in Pemphigus Group Diseases

\begin{tabular}{|c|c|c|}
\hline Diseases & lg & Antigen \\
\hline $\begin{array}{l}\text { Pemphigus vulgaris, mucosal dominant type } \\
\text { Pemphigus vulgaris, mucocutaneous type }\end{array}$ & $\begin{array}{l}\operatorname{Ig} G \\
\operatorname{IgG}\end{array}$ & $\begin{array}{l}\text { Dsg3 } \\
\text { Dsg3 + Dsg1 }\end{array}$ \\
\hline Pemphigus vegetans & $\operatorname{IgG}$ & Dsg3, Dsg1, Dsc3 \\
\hline Pemphigus herpetiformis & IgG & Dsg1, (Dsg3), Dscs \\
\hline Pemphigus foliaceus & IgG & Dsg1 \\
\hline Pemphigus erythematosus & IgG & Dsg1 \\
\hline Paraneoplastic pemphigus & IgG & $\begin{array}{l}\text { Plectin, epiplakin, desmoplakin I/II, BP230, envoplakin, } \\
\text { periplakin, Dsg3, Dsg1, Dscs, } \alpha-2-\text { macroglobulin-like-1 }\end{array}$ \\
\hline IgA pemphigus, subcorneal pustular dermatosis type & $\operatorname{Ig} \mathrm{A}$ & Dsc1 \\
\hline $\begin{array}{l}\text { IgA pemphigus, intraepidermal neutrophilic type IgA } \\
\text { dermatosis }\end{array}$ & $\operatorname{IgA}$ & Unknown \\
\hline
\end{tabular}

$\mathrm{BP}$ = bullous pemphigoid; Dsc = desmocollin; Dsg = desmoglein; Ig = immunoglobulin . 
Table 3. Classification and Autoantigens in Autoimmune Bullous Disorders of the Pemphigoid Type

\begin{tabular}{|l|l|l|}
\hline \multicolumn{1}{|c|}{ Diseases } & \multicolumn{1}{c|}{ Ig } & \multicolumn{1}{c|}{ Antigen } \\
\hline Bullous pemphigoid & Ig & BP180, BP230 \\
\hline Pemphigoid gestationis & Ig & BP180, BP230 \\
\hline Linear IgA dermatosis & IgA & BP180 \\
\hline Mucous membrane pemphigoid & IgG/IgA & BP180, BP230, laminin 332, $66 \beta 4$ integrin \\
\hline Anti-laminin $\gamma-1$ pemphigoid & IgG & Laminin $\gamma-1(p 200)$ \\
\hline Lichen planus pemphigoid & IgG & BP180, BP230 \\
\hline Epidermolysis bullosa acquisita & IgG & Type VII collagen \\
\hline Dermatitis herpetiformis & IgA $(\operatorname{IgG})$ & $\begin{array}{l}\text { Epidermal transglutaminase, tissue } \\
\text { transglutaminase, deamidated gliadin }\end{array}$ \\
\hline
\end{tabular}

$\mathrm{BP}=$ bullous pemphigoid; Ig = immunoglobulin.

The yearly incidence of BP reported in European prospective studies varies between 2.5 and $13 /$ million [5,6]. The largest series of patients $(\mathrm{N}=869)$ collected in a retrospective historical cohort from the UK showed higher incidence rates of 42.8/million [10]. Rising incidence rates of BP in Europe have been linked to risk factors, including population aging; drugs, in particular antidiabetics; diuretics; phenothiazines; major cognitive impairment; and disabling neurological disorders [3,11]. BP affects mostly the elderly: it is generally seen in individuals older than 70 years. Overall incidence is higher in females [3].

\section{Genetics}

There is evidence that genetics plays a critical role in PV development, severity, and prognosis. An increased frequency of HLA-DRB1*04:02 haplotypes in Ashkenazi Jewish patients [12] and DQB1*05:03 in non-Jewish Caucasian populations [13] has been observed. The coexistence of alleles of DRB1*14/DQB1*05 and A*11/DQB1*05 would be strongly influential for the predisposition to the disease, while that of HLA-B*50/DQB1*02 could play a protective role [14]. In addition, multiple single nucleotide polymorphisms within different genes may confer susceptibility to the diseases, probably in a population-specific way [15].

Serological typing for HLA class II antigens in patients with $\mathrm{ABD}$ of the pemphigoid type revealed a highly significant association with HLA-DQ $\beta 1 * 0301$ [16].

\section{Pathophysiology}

PV and BP are characterized by the loss of tolerance to autoantigens expressed primarily in the skin, in particular desmosomal proteins in PV and components of the hemidesmosomes in BP.

In PDs, the production of pathogenic immunoglobulin $G$ (IgG) autoantibodies, mainly IgG4, against the desmosomal cadherins Dsg1 and Dsg3, causes loss of epidermal keratinocyte adhesion. Dsg3-specific autoreactive T cells are deleted in periphery, and regulatory $\mathrm{T}$ cells (Tregs) play an important role in such peripheral tolerance [17]. Environmental factors, in particular pathogens, have been hypothesized as causes of reverting immunological tolerance with resulting autoantibody production [18]. A possible link with rotavirus infection has been suggested because of cross-reactive VH1-46 antibodies, which are able both to disrupt keratinocyte adhesion and inhibit rotavirus replication [19]. An additional relationship between the exposure to a noninfectious environmental antigen and the development of an autoimmune response to self-antigen has been documented in fogo selvagem, the endemic form of PF. In this condition, cross-reactive epitopes on Dsg1 and LJM11 sand fly salivary gland antigen could drive the production of pathogenic IgG4 autoantibodies anti-Dsg1 [20].

Although antibody-mediated disease mechanisms in PV are widely characterized, the $\mathrm{T}$ cell implication has to be better clarified. Autoreactive CD4+ T lymphocytes have been implicated in the regulation of the production of pathogenic anti-Dsg3 autoantibodies by B cells [21]. There is a strong association between PV and distinct major histocompatibility complex class II haplotypes, which are considered essential for the presentation of specific Dsg3 peptides to autoreactive CD4+ helper T cells $[18,22]$.

The causes of loss of tolerance leading to the production of antibodies anti-BP180/collagen XVII and BP230/dystonin, and less frequently also against other antigens in BP, are not known. BP has been linked to environmental factors as physical agents, such as radiation therapy, ultraviolet radiation [23] trauma, neurodegeneration or neuroinflammation [24] and drugs, in particular gliptins [25]. Muramatsu et al demonstrated that Tregs are essential in preventing the spontaneous production of BP autoantibodies as well [26]. An imbalance between autoreactive helper $\mathrm{T}$ cells and Tregs and a $\mathrm{T}$ cell-independent activation of a toll-like receptor 


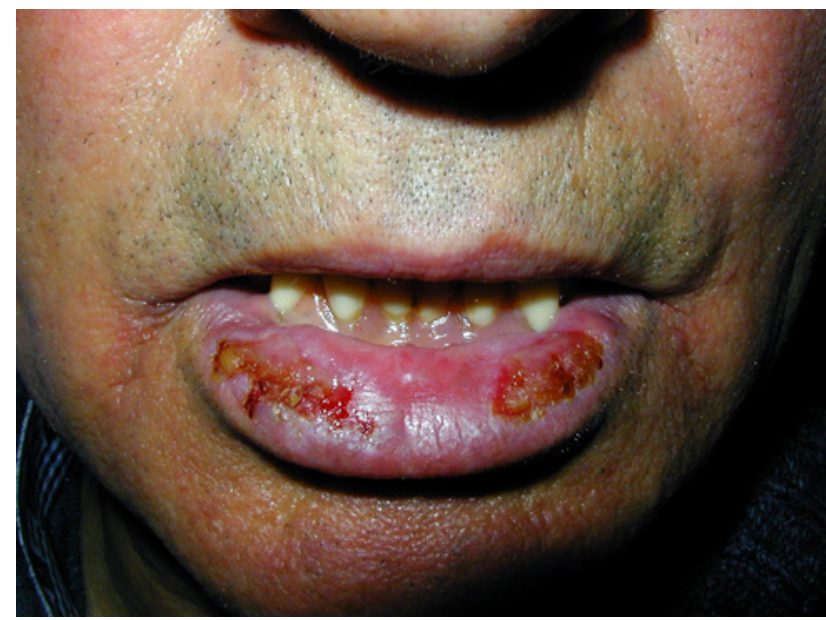

Figure 1. Solitary lip ulcerations as highly unusual manifestations of pemphigus.

system could underlie a B cell stimulation, with resulting BP autoantibody production [24].

\section{Clinical Presentation}

PV, the most frequent and severe form of pemphigus, affects both skin and mucosal surfaces. The disease often begins in the oral mucosa with superficial, flaccid blisters that rapidly rupture, leaving slow-healing, painful, moist erosions that may make oral intake difficult and cause pain and fetor as well. Accompanying symptoms are sialorrhea and bloody saliva. Involvement of other skin areas may occur from weeks to months later. In addition to the cutaneous and mucosal surfaces of the mouth (Figure 1), the pharynx, vocal folds, and anogenital mucosa may also be affected. Scalp involvement is observed in up to $60 \%$ of patients (Figure 2). Clinical variants include mucosal-only disease (which correlates with circulating anti-Dsg3 autoantibodies), cutaneous-only disease (anti-Dsg1 antibody predominant), or more frequently, mucocutaneous involvement (presence of both anti-Dsg1 and anti-Dsg3 antibodies). Recently, clinical scores of disease severity have been implemented. The Pemphigus Disease Area Index and Autoimmune Bullous Skin Disorder Intensity Score have been recognized as robust tools to correctly assess disease activity [27].

Classic BP affects elderly individuals, usually above age 70 years. The spectrum of clinical presentation is highly variable. In a consistent proportion of patients, the blistering eruption is preceded by a prodromal nonbullous phase, usually lasting weeks to months and even, in rare cases, remaining the only manifestation of the disease [28]. During the nonbullous phase, pruritic, erythematous, or urticarial patches and plaques occur. Also eczematous, polycyclic, targetoid, nodular, or lichenoid lesions may be observed (Figure 3). The bullous phase is characterized by tense bullae on an erythematous, urticarial base, localized or widespread

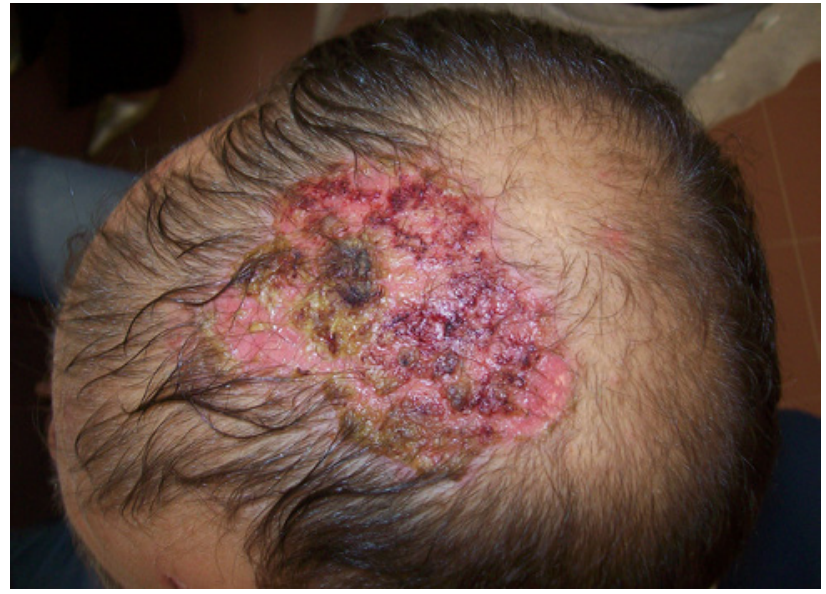

Figure 2. Erosions, crusted and scaly plaques in a case of pemphigus of the scalp. The scalp shows an abundance of desmogleins in hair follicles and may be the first location of the disease.

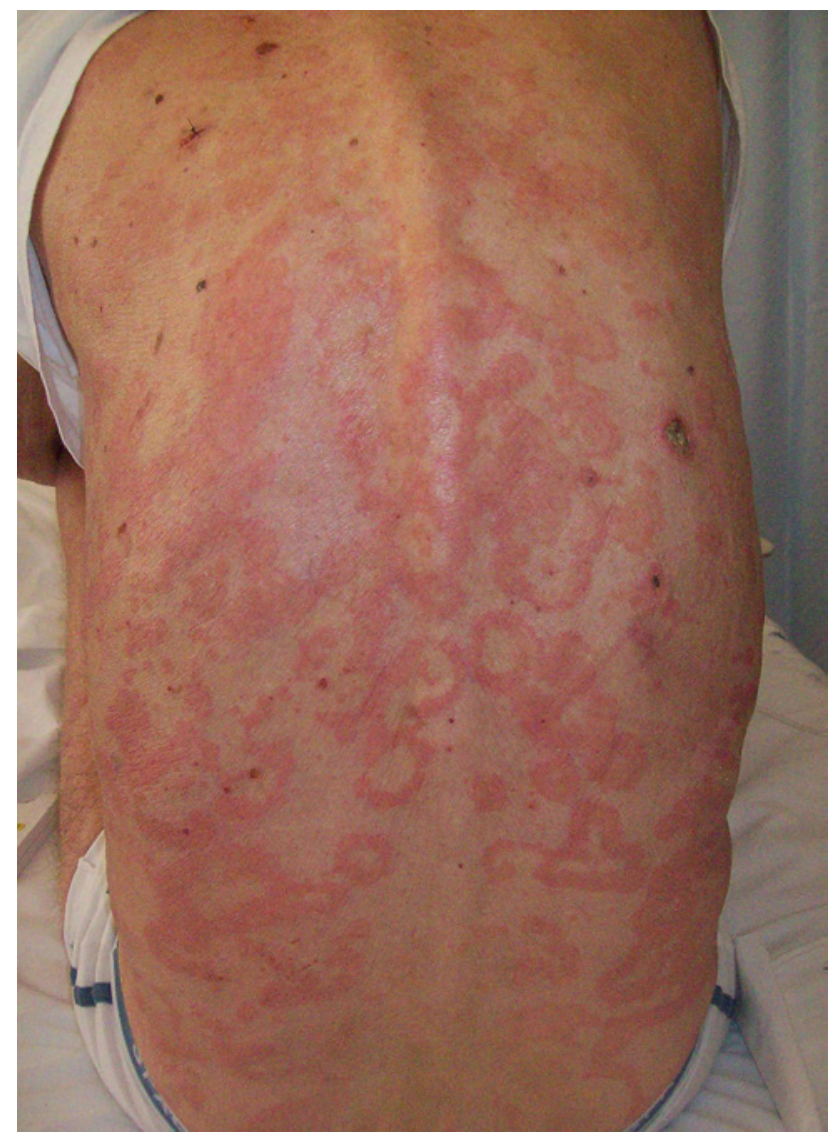

Figure 3. Numerous polycyclic and targetoid lesions during the nonbullous phase of bullous pemphigoid.

(Figures 4 and 5). Pruritus is common and often severe. After rupture, bullae leave moist erosions and crusts that resolve without scarring. Mucosal involvement may be observed in $10 \%$ to $30 \%$ of the cases with oral, esophageal, and genital involvement. Two disease scores, the BP Disease Area Index and the Autoimmune Bullous Skin Disorder Intensity Score, have shown significant reliability, validity, and responsiveness [29-31]. BP shows a different clinical course in infants and 


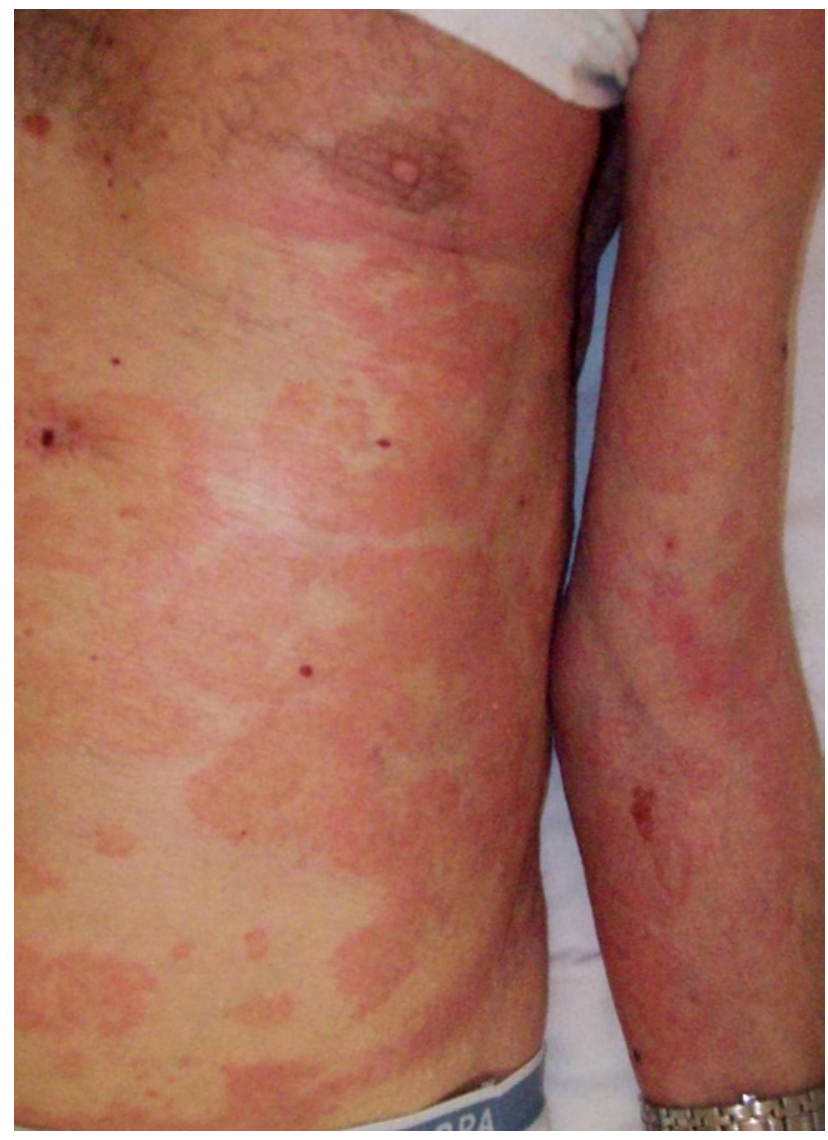

Figure 4. Urticarial and polycyclic lesions of the nonbullous phase of bullous pemphigoid associated with a tense bulla on the flexor surface of a forearm.

children. Acral involvement is common, especially on the face (62\%), palms and soles (79\%); localized lesions on the genital area may be observed in $17 \%$ of cases [32].

\section{Diagnosis}

Clinical presentations of ABDs often overlap, and diagnosis may not be easily made on the basis of clinical features alone. Therefore, ABDs are usually diagnosed using 3 criteria: (1) the overall clinical picture, including patient history and physical examination; (2) histopathology; and (3) a positive direct immunofluorescence (DIF) microscopy, usually performed on perilesional skin, or serological detection of autoantibodies against the involved epithelial antigens [22]. Immunodiagnostic tests are particularly useful to differentiate the various diseases.

\section{Histopathology}

\section{Pemphigus Vulgaris}

Biopsy should be taken in an early intact blister. When only erosions are present, as usually happens in the oral area, a biopsy should be obtained from the active border of a denuded area. The characteristic histological finding is an

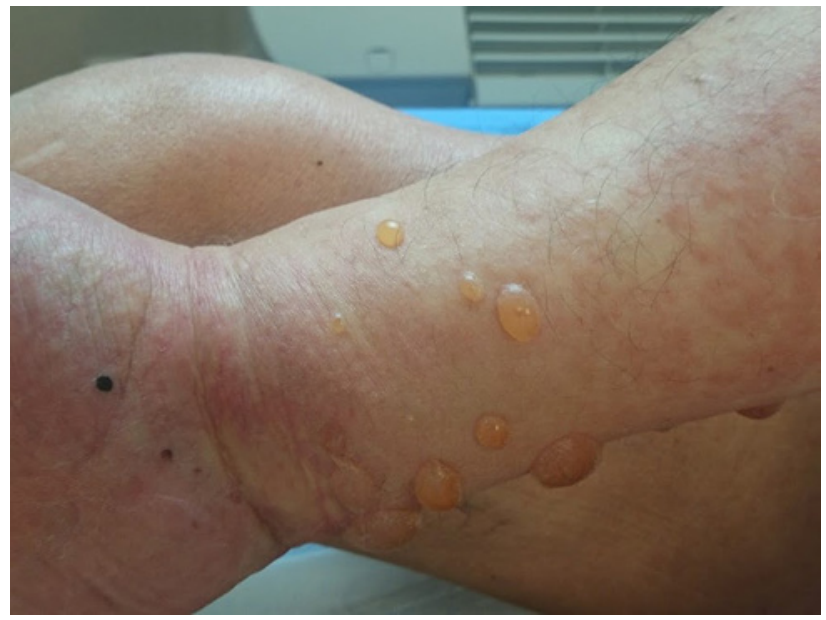

Figure 5. Typical tense bullae on an erythematous base in a patient with bullous pemphigoid.

intraepidermal blister caused by acantholysis, which consists of the separation of keratinocytes just above the basal cell layer due to a loss of the normal cell attachment. In the cavity of the blister, a few inflammatory cells, in particular eosinophils, may be observed. The surrounding inflammation is minimal [22]. Eosinophilic spongiosis may be the only histological feature of pemphigus in the initial stages. In such cases eosinophils invade a spongiotic epidermis without evidence of acantholysis.

Single or grouped acantholytic cells can be quickly documented by cytological examination (Tzanck cytodiagnostic test). After opening of an intact roof of a blister, material has to be scraped from the base of a vesicle or blister and smeared onto a microscopic slide. After air-drying, samples are commonly stained with May-Grünwald-Giemsa and evaluated. This test does not replace histological examination, since acantholytic keratinocytes may also be observed in other dermatoses as a secondary phenomenon to inflammation or ballooning degeneration.

\section{Bullous Pemphigoid}

The histopathological assessment of an early bulla shows a subepidermal blister containing a net of fibrin with a variable number of eosinophils and/or neutrophils accompanied by a dermal inflammatory infiltrate mainly consisting of eosinophils and neutrophils [3,33]. In the nonbullous phase, histopathological findings may be nonspecific, since only subepidermal clefts and eosinophilic spongiosis may be observed [34].

\section{Direct Immunofluorescence}

DIF is the most reliable and sensitive diagnostic test for ABDs for the most part. However, nonspecific staining may occasionally be seen in other cutaneous disorders with occasional false-positive findings $[35,36]$. DIF investigates the skin or 
mucous membrane and shows antibody deposition on the keratinocyte cell surface (in PDs) or along the basement cell membrane (in BP).

\section{Pemphigus Vulgaris}

Biopsy of perilesional skin or mucosa shows deposits of $\mathrm{IgG}$ at the keratinocyte cell membrane [22,37]. IgG deposition is seen in up to $100 \%$ of patients with active disease. Complement (C3) deposition may not be observed, since IgG4, the dominant subclass of IgG involved in PV, does not fix complement.

\section{Bullous Pemphigoid}

It is best to biopsy perilesional skin from a recent blister. The diagnostic hallmark consists of fine, linear, continuous deposits of IgG and/or C3 along the dermal-epidermal junction. Occasionally IgA and IgE may be observed showing a similar pattern [33,38]. Salt-split technique is a useful tool in the differential diagnosis of other ABDs, such as epidermolysis bullosa acquisita, which shows a similar DIF pattern. In BP, immune deposits are found in the epidermal side or mixed at both the epidermal and dermal sites of the split (n-serration pattern), while in epidermolysis bullosa acquisita, deposits are typically localized on the dermal side of the cleavage (u-serration pattern).

\section{Serological Studies}

The method of serological detection of the autoantibodies largely relies on indirect immunofluorescence (IIF) and enzyme-linked immunosorbent assay (ELISA) tests. Recently, novel diagnostic multivariant assays were developed as practical screening tools for patients with suspected ABD with the aim of processing the most common autoantibodies simultaneously $[39,40]$.

\section{Pemphigus Vulgaris}

IIF allows for the detection of circulating autoantibodies against proteins or epithelial keratinocytes by incubating patient serum with appropriate commercially available substrates containing the target antigen. The testing study is conducted on monkey esophagus or epithelial substrates. PV sera produces a characteristic smooth and reticular pattern on most epithelial layer, referred as "fishnet-like," "chicken wire," or "honeycomb" pattern [37,38].

Cloning of the gene coding for the major pemphigus antigens, Dsg1 and Dsg3, has enabled the production of recombinant proteins, which are used to detect IgG autoantibodies by ELISA [41]. The Dsg3/Dsg1 autoantibody profile defines the clinical outcome, since PV with exclusive involvement of the mucous membranes is associated with $\operatorname{IgG}$ against Dsg3, while the mucocutaneous variant of PV is associated with both anti-Dsg1 and anti-Dsg3 IgG. The detection of IgG autoantibodies by ELISA is positive in more than $90 \%$ of cases [37]. The titers of serum IgG autoantibodies against
Dsg1 and Dsg3 generally correlate with the extent and clinical activity of disease, and high levels of anti-Dsg1 by ELISA has a positive predictive value for skin relapses [37]. Therefore, ELISA may represent a good serological marker of disease activity, although evidence about its predictive value from large prospective cohort studies is lacking [37]. One must keep in mind that anti-Dsg antibodies have been occasionally discovered in sera of normal patients and those affected with other bullous diseases [41]. In addition, a small number of pemphigus patients may not show the PV phenotype expected by their Dsg autoantibody serum profile [42].

\section{Bullous Pemphigoid}

IIF may demonstrate circulating IgG antibodies binding to the basal membrane. The most specific test substrate for BP is salt-split skin, which is healthy human skin in which subepidermal splitting was induced by $1 \mathrm{~mol} / \mathrm{L}$ sodium chloride solution [43]. Other substrates include monkey or rabbit esophagus, with possible lower sensitivity [38].

ELISA test may show anti-BP180 and anti-BP230 IgG antibodies. The serum level of anti-BP180 antibodies may be monitored during the course of the disease. High titers of anti-BP180 NC16A IgG after therapy cessation are considered a predictor of risk of relapse. Even then, the test result may be positive in healthy individuals or in individuals with other pruritic, inflammatory skin disorders [38].

\section{Therapeutic Management}

Because of their chronic nature, ABDs may last for a lifetime or for several years with a high tendency to relapse. PV is a potentially life-threatening skin disorder that requires early recognition and prompt treatment. BP is highly associated with old age, distinct drugs, and neurological and psychiatric diseases. Treatment depends on the extent and severity of disease. In both conditions the primary objective is to promote healing of the bullous and erosive cutaneous and/or mucous lesions. Additional goals are to reduce itch, prevent or reduce the recurrences of the blistering eruptions, improve the quality of life of patients, and minimize and identify as quickly as possible serious side effects associated with long-term treatment, particularly in the elderly [37,38]. A complete medical history focusing on drug history and comorbid diseases that may affect treatment decisions is mandatory. A complete biochemistry screening should be conducted and should include liver and renal function tests.

\section{Treatment}

\section{Pemphigus Vulgaris}

The morbidity and mortality of PV have remained high owing to complications of therapy, such as pneumonia, septicemia, 
Table 4. Dosage and Pretreatment Investigations for Rituximab in Pemphigus Vulgaris

\section{Rituximab Dosage}

Pretreatment Investigations

Two 1,000-mg intravenous infusions separated by 2 weeks [1]; lower doses $(500 \mathrm{mg}$ ) may be used for retreatment (at month 12 and every 6 months thereafter); methylprednisolone $100 \mathrm{mg}$ intravenous or equivalent glucocorticoid is recommended 30 minutes prior to each infusion

\section{Contraindications} Adverse Events

Complete blood cell count, liver and renal function tests, creatinine, interferon gamma release assay, hepatitis $\mathrm{B}$ and hepatitis $\mathrm{C}$ markers, HIV antibodies, chest X-ray, ECG, cardiological examination

Active, severe
infections, severely
immunocompromised state,
severe heart failure (New
York Heart Association
class IV) or severe,
uncontrolled cardiac disease,
cardiomyopathy, ischemic
heart disease, severe
arrhythmias such as rapid
atrial fibrillation, frequent
premature ventricular
contractions

Infusion reactions, depression, infections, cardiac disorders, rare cases of fatal progressive multifocal leukoencephalopathy

The dosing protocol corresponds to that of the European Medicine Agency's "Summary of product characteristics" and US Food and Drug Administration's highlights of prescribing information. Different dosing protocols are reported in expert recommendations and therapeutic guidelines [42,50].

and cardiovascular disease. Therefore, correct management of the comorbidities of pemphigus is crucial to decrease disease-associated morbidity and mortality. The traditional treatment paradigm of PV relies on systemic corticosteroid immunosuppression. Prednisone is usually given at $0.5-1.5$ $\mathrm{mg} / \mathrm{kg} /$ day as a typical initial dosage. The therapeutic effect is evaluated by the number of new blisters per day and the ability to stop the blistering eruption. In refractory cases, the initial dose may be increased to $2 \mathrm{mg} / \mathrm{kg} /$ day. On the other hand, if clinical remission is obtained and no new blisters occur, glucocorticoids may be gradually tapered. Appropriate steroid-tapering strategies may prevent relapses, although an optimal treatment regimen remains indeterminable because of the lack of evidence. A decrease in the titers of circulating autoantibodies may drive tapering decisions. Recommendations by an international expert panel are to check serum autoantibodies at the initiation of treatment, after 3 months and every 3-6 months, or in case of relapse [44]. Control of disease activity is usually achieved within several weeks, whereas complete remission of quiescent disease on minimal treatment ( $\leq 10 \mathrm{mg} /$ day prednisone) more often requires several months. Long-term, complete remission off treatment may require years of therapy [45].

Additional immunosuppressive adjuvants, such as azathioprine (1-3 mg/kg/day) or mycophenolate mofetil (2 g/ day), are often administered at initiation of treatment or in refractory cases in order to achieve faster or better control of the disease and spare corticosteroids, respectively. Second-line adjuvants include cyclophosphamide, methotrexate, intravenous immunoglobulins, and immunoadsorption. The latter treatment consists of the passive removal of $\mathrm{IgG}$ from the patient's systemic circulation. When complete remission is obtained with combined therapy, the dosage of the immu- nosuppressive adjuvant drug is continued, while the prednisone is gradually tapered. No particular advantage has been found with intravenous corticosteroid pulse treatment over treatment with oral corticosteroids [46].

Rituximab, a chimeric monoclonal antibody targeting the CD20 antigen of B lymphocytes, has recently emerged as a highly promising therapeutic option for PV. Rituximab causes B-cell depletion and a subsequent reduction in pathogenic autoantibodies. Pretreatment investigations, contraindications, and treatment schedules are summarized in Table 4. Rituximab is one of the only drugs to gain European Medicine Agency and US Food and Drug Administration approval for the treatment of PV. Previous clinical experiences showed its dramatic efficacy as second- or third-line treatment in severe recalcitrant or relapsing cases of PV [47,48]. In particular, a meta-analysis including 578 patients with pemphigus showed a remission rate of $76 \%$ following a single cycle of rituximab, with a relapse rate of $20 \%$ (2 years) to $60 \%$ (5 years) [49]. More robust evidence showed a higher efficacy when it was administered early in the course of the disease [50]. Ritux 3, a prospective, open-label, randomized clinical trial investigated rituximab as first-line treatment in combination with short-term prednisone vs prednisone alone for the treatment of pemphigus. Results showed that first-line use of rituximab plus short-term prednisone for patients with pemphigus is more effective than using prednisone alone, with fewer adverse events [50]. At month $24,89 \%$ of 46 patients assigned to rituximab plus short-term prednisone were in complete remission off therapy vs $34 \%$ of 44 assigned to prednisone alone. A post hoc analysis of the enrolled patients in the Ritux 3 study showed a steroid-sparing effect of rituximab, with rituximab-treated patients having lower cumulative 


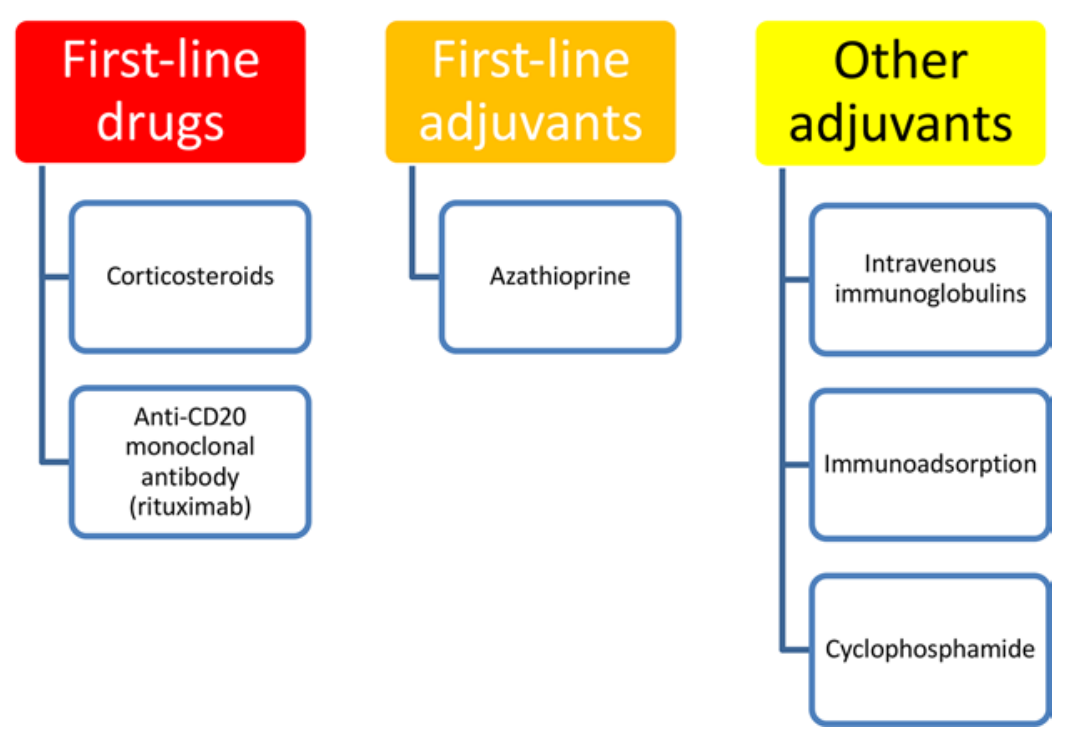

Figure 6. Treatment options for pemphigus.

doses of corticosteroids and experiencing less severe or life-threatening corticosteroid-related adverse events [51]. Therefore, intravenous rituximab is now recommended as first-line option for new-onset moderate to severe pemphigus, but also for previously treated patients who do not achieve clinical remission with systemic corticosteroids and/ or immunosuppressive adjuvants [44,52].

The introduction of rituximab presents an opportunity to change the traditional therapeutic approach to PV. A complete remission off therapy may represent a realistic expectation for many patients. Many aspects remain to be deepened. B-cell repopulation, low CD41 T-cell count, persistence of anti-Dsg1 (>20 IU) and Dsg3 (>120 IU) at month 3, and severe Pemphigus Disease Area Index score at baseline $(>45)$ were identified as predictors of relapse in patients treated with rituximab $[53,54]$. Additional areas that deserve further studies are the combination protocols with corticosteroids, the possibility of using CD20 inhibitors alone, prevention of relapses, the role of anti-Dsg ELISA values as biomarkers to drive further infusions, and the benefit from combining other adjuvants in patient management. Consequently, the therapeutic algorithm of PV could be redefined in the future (Figure 6).

Topical therapy of PV is essentially symptomatic and is practiced to alleviate inflammation and prevent secondary infections. Usually corticosteroids, calcineurin inhibitors or corticosteroids and antibiotics in combination are administered on the cutaneous and mucous lesions. Cutaneous erosive lesions should be covered using low-adhesive wound dressings. Supportive care for oral lesions includes gel-containing local anesthetics and proper dental care.

Limited experience proved rituximab useful in refractory $\mathrm{PF}$ as well $[55,56]$.

\section{Bullous Pemphigoid}

Although there is no generally accepted classification of disease severity, a classification of BP into mild $(<10 \%$ affected body surface area), moderate, and severe forms has been suggested [57]. The effectiveness of topical therapy with superpotent topical corticosteroids in localized and moderate forms of BP is supported by a Cochrane review [38,58]. Be aware that the dose of $40 \mathrm{~g}$ every day or 10 to $30 \mathrm{~g}$ every day $[59,60]$, which has proven equally effective as systemic prednisolone, is equivalent to about a tube per day. Practicability and limitations of this drug regimen are that for some patients with BP, a twice-daily topical application [57] on widespread areas or the daily purchase of an ointment tube may not be manageable. In the localized, nonsevere forms, immunomodulatory, nonimmunosuppressant drugs such as doxycycline may be considered a viable option [61]. Although its exact mechanism of action is not well understood, doxycycline proved to be not inferior to oral prednisolone for short-term blister control and is safer in the long term $[61,62]$. Systemic corticosteroid therapy (prednisone $0.5 \mathrm{mg} / \mathrm{kg} / \mathrm{day}$ ) represents the treatment of choice for severe forms [38]. For maintenance treatment, doses may be tapered gradually within 4 to 6 months of initiation of treatment. Adjunctive therapy includes combination with azathioprine, mycophenolate mofetil, tetracyclines plus nicotinamide, methotrexate, and dapsone [63] (Figure 7). Bacterial superinfection of erosions should be treated with local antiseptics. Wound dressings should be considered for large wounds. Sterile puncture of large blisters is recommended [57]. Available data suggest that rituximab may provide clinical benefits for patients with refractory BP [64], although with less effectiveness. A complex interplay of complement activation of IgG autoantibodies deposited 


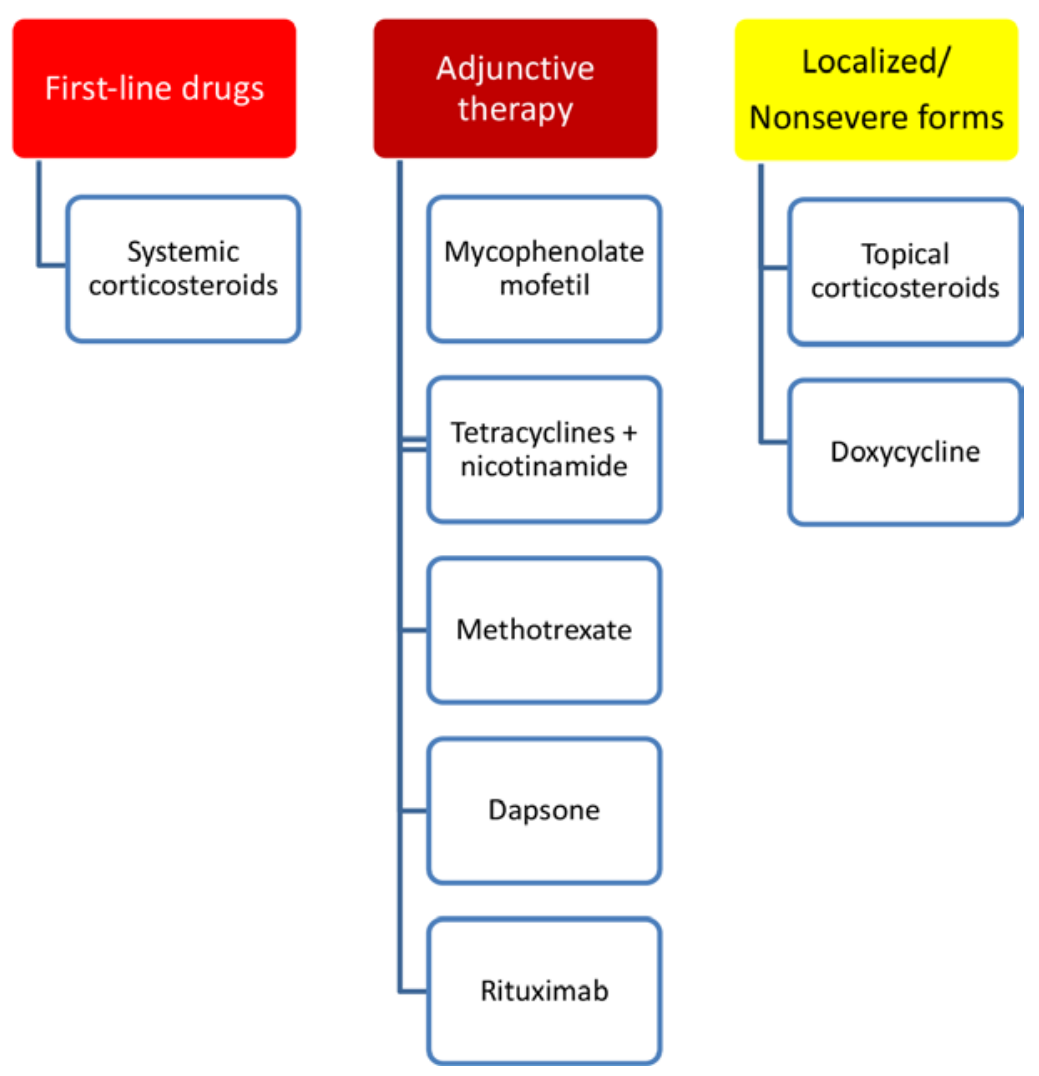

Figure 7. Treatment options for bullous pemphigoid.

at the dermal-epidermal basement membrane zone and inflammatory response might be not fully ruled by a B-cell downregulation and a decrease in autoantibody titers [65].

Recent studies support a pathogenic role of $\operatorname{IgE}$ in the development of BP. This hypothesis is endorsed by the finding of $\operatorname{IgE}$ deposition in the basement membrane zone in patients with BP. In addition, there is correlation between serum levels of IgE autoantibodies against BP180 and BP disease activity [62]. Use of IgE targeted therapies, such as omalizumab, has been shown as promising in recent studies [66], with $80 \%$ complete response rates and mean time to recurrence of 3.4 months [64].

\section{Conclusions}

Current treatment paradigms in ABD are traditionally based on the administration of immunosuppressive drugs, often in combination. The advent of rituximab, the monoclonal IgG antibody against CD20, has revolutionized the treatment of pemphigus, indicating that a complete remission off therapy is now possible. Therefore, additional studies are investigating other anti-CD20 monoclonal antibodies [67]. Ideally, therapy for autoimmune diseases should eliminate pathogenic autoimmune cells without affecting protective immunity. Innovative approaches include antigen-specific immune suppression in PV by therapeutic immunoadsorption of pathogenic autoantibodies [68,69]. A promising approach is the use of reengineering chimeric autoantibody receptor $\mathrm{T}$ cells. Patient-derived T cells are modified ex vivo to express a chimeric antibody receptor, which allows selective recognition and consequent killing of anti-Dsg3 autoreactive B lymphocytes [70,71]. Also in BP, new therapeutic targets aim to provide new treatment strategies that may go beyond nonspecific immunosuppression. In addition to omalizumab, monoclonal antibodies to IL-5 such as mepolizumab and bertilimumab, an anti-eotaxin-1 antibody, are currently being investigated in BP [65]. In the context of immunomodulatory drugs, dimethyl fumarate, which is a prodrug utilized in psoriasis and multiple sclerosis, is also under investigation for BP because of its pleotropic anti-inflammatory effects [72].

\section{References}

1. Kridin K. Pemphigus group: overview, epidemiology, mortality, and comorbidities. Immunol Res. 2018;66(2):255-270. https:// doi.org/10.1007/s12026-018-8986-7

2. Daniel BS, Murrell DF. Review of autoimmune blistering diseases: the Pemphigoid diseases. J Eur Acad Dermatol Venereol. 2019;33(9):1685-1694. https://doi.org/10.1111/jdv.15679

3. Alpsoy E, Akman-Karakas A, Uzun S. Geographic variations in epidemiology of two autoimmune bullous diseases: pemphigus 
and bullous pemphigoid. Arch Dermatol Res. 2015;307(4):291298. https://doi.org/10.1007/s00403-014-1531-1

4. Marazza G, Pham HC, Schärer L, et al. Incidence of bullous pemphigoid and pemphigus in Switzerland: a 2-year prospective study. Br J Dermatol. 2009;161(4):861-868. https://doi. org/10.1111/j.1365-2133.2009.09300.x

5. Bertram F, Bröcker EB, Zillikens D, et al. Prospective analysis of the incidence of autoimmune bullous disorders in Lower Franconia, Germany. J Dtsch Dermatol Ges. 2009;7(5):434-440. https:// doi.org/10.1111/j.1610-0387.2008.06976.x

6. Baican A, Baican C, Chiriac G, et al. Pemphigus vulgaris is the most common autoimmune bullous disease in Northwestern Romania. Int J Dermatol. 2010;49(7):768-774. https://doi. org/10.1111/j.1365-4632.2009.04345.x

7. Pisanti S, Sharav Y, Kaufman E, Posner LN. Pemphigus vulgaris: incidence in Jews of different ethnic groups, according to age, sex, and initial lesion. Oral Surg Oral Med Oral Pathol. 1974;38(3):382-387. https://doi.org/10.1016/00304220(74)90365-X

8. Chams-Davatchi C, Valikhani M, Daneshpazhooh M, et al. Pemphigus: analysis of 1209 cases. Int J Dermatol. 2005;44:470-476. https://doi.org/10.1111/j.1365-4632.2004.02501.x

9. Simon DG, Krutchkoff D, Kaslow RA, Zarbo R. Pemphigus in Hartford County, Connecticut, from 1972 to 1977. Arch Dermatol. 1980;116(9):1035-1037. https://doi.org/10.1001/ archderm.1980.01640330073017

10. Langan SM, Smeeth L, Hubbard R, Fleming KM, Smith CJ, West J. Bullous pemphigoid and pemphigus vulgaris-incidence and mortality in the UK: population based cohort study. BMJ. 2008;337(7662):a180. https://doi.org/10.1136/bmj.a180

11. Bastuji-Garin S, Joly P, Lemordant P, et al. Risk factors for bullous pemphigoid in the elderly: a prospective case-control study. $J$ Invest Dermatol. 2011;131(3):637-643. https://doi.org/10.1038/ jid.2010.301

12. Ahmed AR, Yunis EJ, Khatri K, et al. Major histocompatibility complex haplotype studies in Ashkenazi Jewish patients with pemphigus vulgaris. Proc Natl Acad Sci U S A. 1990;87(19):76587662. https://doi.org/10.1073/pnas.87.19.7658

13. Ahmed AR, Wagner R, Khatri K, et al. Major histocompatibility complex haplotypes and class II genes in non-Jewish patients with pemphigus vulgaris. Proc Natl Acad Sci U S A. 1991;88(11):50565060. https://doi.org/10.1073/pnas.88.11.5056

14. Sun Y, Liu H, Yang B, et al. Investigation of the predisposing factor of pemphigus and its clinical subtype through a genome-wide association and next generation sequence analysis. J Eur Acad Dermatol Venereol. 2019;33(2):410-415. https://doi.org/10.1111/ jdv.15227

15. Mahmoudi H, Ebrahimi E, Daneshpazhooh M, et al. Single-nucleotide polymorphisms associated with pemphigus vulgaris: potent markers for better treatment and personalized medicine. Int J Immunogenet. 2020;47(1):41-49. https://doi.org/10.1111/iji.12451

16. Delgado JC, Turbay D, Yunis EJ, et al. A common major histocompatibility complex class II allele HLA-DQB1* 0301 is present in clinical variants of pemphigoid. Proc Natl Acad Sci U S A. 1996;93(16):8569-8571. https://doi.org/10.1073/ pnas.93.16.8569

17. Di Zenzo G, Amber KT, Sayar BS, Müller EJ, Borradori L. Immune response in pemphigus and beyond: progresses and emerging concepts. Semin Immunopathol. 2016;38(1):57-74. https://doi. org/10.1007/s00281-015-0541-1
18. Takahashi $\mathrm{H}$, Iriki $\mathrm{H}$, Mukai $\mathrm{M}$, et al. Autoimmunity and immunological tolerance in autoimmune bullous diseases. Int Immunol. 2019;31(7):431-437. https://doi.org/10.1093/intimm/dxz030

19. Cho MJ, Ellebrecht CT, Hammers CM, et al. Determinants of VH146 cross-reactivity to pemphigus vulgaris autoantigen desmoglein 3 and rotavirus antigen VP6. J Immunol. 2016;197(4):1065-1073. https://doi.org/10.4049/jimmunol.1600567

20. Qian Y, Jeong JS, Ye J, et al. Overlapping IgG4 responses to selfand environmental antigens in endemic pemphigus foliaceus. J Immunol. 2016;196(5):2041-2050. https://doi.org/10.4049/ jimmunol.1502233

21. Schmidt E, Kasperkiewicz M, Joly P. Pemphigus. Lancet. 2019;394(10201):882-894. https://doi.org/10.1016/S0140-6736 (19)31778-7

22. Pollmann R, Schmidt T, Eming R, Hertl M. Pemphigus: a comprehensive review on pathogenesis, clinical presentation and novel therapeutic approaches. Clin Rev Allergy Immunol. 2018;54(1):125. https://doi.org/10.1007/s12016-017-8662-z

23. Lo Schiavo A, Ruocco E, Brancaccio G, Caccavale S, Ruocco V, Wolf R. Bullous pemphigoid: etiology, pathogenesis, and inducing factors: facts and controversies. Clin Dermatol. 2013;31(4):391399. https://doi.org/10.1016/j.clindermatol.2013.01.006

24. Genovese G, Di Zenzo G, Cozzani E, Berti E, Cugno M, Marzano AV. New insights into the pathogenesis of bullous pemphigoid: 2019 update. Front Immunol. 2019;10:1506. https://doi. org/10.3389/fimmu.2019.01506

25. Plaquevent M, Tétart F, Fardet L, et al. Higher frequency of dipeptidyl peptidase-4 inhibitor intake in bullous pemphigoid patients than in the French general population.J Invest Dermatol. 2019;139(4):835-841. https://doi.org/10.1016/j.jid.2018.10.045

26. Muramatsu K, Ujiie H, Kobayashi I, et al. Regulatory T-cell dysfunction induces autoantibodies to bullous pemphigoid antigens in mice and human subjects. J Allergy Clin Immunol. 2018;142(6):1818-1830. https://doi.org/10.1016/j.jaci.2018. 03.014

27. Hébert V, Boulard C, Houivet E, et al. Large international validation of ABSIS and PDAI pemphigus severity scores. J Invest Dermatol. 2019;139(1):31-37. https://doi.org/10.1016/ j.jid.2018.04.042

28. Cozzani E, Gasparini G, Burlando M, Drago F, Parodi A. Atypical presentations of bullous pemphigoid: clinical and immunopathological aspects. Autoimmun Rev. 2015;14(5):438-445. https://doi. org/10.1016/j.autrev.2015.01.006

29. Murrell DF, Daniel BS, Joly P, et al. Definitions and outcome measures for bullous pemphigoid: recommendations by an international panel of experts. J Am Acad Dermatol. 2012;66(3):479485. https://doi.org/10.1016/j.jaad.2011.06.032

30. Pfütze M, Niedermeier A, Hertl M, Eming R. Introducing a novel Autoimmune Bullous Skin Disorder Intensity Score (ABSIS) in pemphigus. Eur J Dermatol. 2007;17(1):4-11.

31. Wijayanti A, Zhao CY, Boettiger D, et al. The reliability, validity and responsiveness of two disease scores (BPDAI and ABSIS) for bullous pemphigoid: which one to use? Acta Derm Venereol. 2017;97(1):24-31. https://doi.org/10.2340/00015555-2473

32. Miyamoto D, Santi CG, Aoki V, Maruta CW. Bullous pemphigoid. An Bras Dermatol. 2019;94(2):133-146. https://doi.org/10.1590/ abd1806-4841.20199007

33. Cozzani E, Marzano AV, Caproni M, Feliciani C, Calzavara-Pinton P; Cutaneous Immunology group of SIDeMaST. Bullous 
pemphigoid: Italian guidelines adapted from the EDF/EADV guidelines. G Ital Dermatol Venereol. 2018;153(3):305-315.

34. Machado-Pinto J, McCalmont TH, Golitz LE. Eosinophilic and neutrophilic spongiosis: clues to the diagnosis of immunobullous diseases and other inflammatory disorders. Semin Cutan Med Surg. 1996;15(4):308-316. https://doi.org/10.1016/\$10855629(96)80044-7

35. Schmidt E, Goebeler M, Hertl M, et al. S2k guideline for the diagnosis of pemphigus vulgaris/foliaceus and bullous pemphigoid. J Dtsch Dermatol Ges. 2015;13(7):713-727. https://doi. org/10.1111/ddg. 12612

36. Miller DD, Bhawan J. Bullous tinea pedis with direct immunofluorescence positivity: when is a positive result not autoimmune bullous disease? Am J Dermatopathol. 2013;35(5):587-594. https://doi.org/10.1097/DAD.0b013e3182604854

37. Feliciani C, Cozzani E, Marzano AV, et al. Italian Guidelines in Pemphigus-adapted from the European Dermatology Forum (EDF) and European Academy of Dermatology and Venerology (EADV). G Ital Dermatol Venereol. 2018;153(5):599-608. https:// doi.org/10.23736/S0392-0488.18.06073-X

38. Feliciani C, Joly P, Jonkman MF, et al. Management of bullous pemphigoid: the European Dermatology Forum consensus in collaboration with the European Academy of Dermatology and Venereology. Br J Dermatol. 2015;172(4):867-877. https://doi. org/10.1111/bjd.13717

39. van Beek N, Dähnrich C, Johannsen N, et al. Prospective studies on the routine use of a novel multivariant enzyme-linked immunosorbent assay for the diagnosis of autoimmune bullous diseases. J Am Acad Dermatol. 2017;76(5):889-894. https://doi. org/10.1016/j.jaad.2016.11.002

40. Yang A, Xuan R, Melbourne W, Tran K, Murrell DF. Validation of the BIOCHIP test for the diagnosis of bullous pemphigoid, pemphigus vulgaris and pemphigus foliaceus. J Eur Acad Dermatol Venereol.2020;34(1):153-160. https://doi.org/10.1111/jdv.15770

41. Amagai M, Komai A, Hashimoto T, et al. Usefulness of enzyme-linked immunosorbent assay using recombinant desmogleins 1 and 3 for serodiagnosis of pemphigus. $\mathrm{Br} J$ Dermatol. 1999;140(2):351-357. https://doi.org/10.1046/j.13652133.1999.02752.x

42. Jamora MJ, Jiao D, Bystryn JC. Antibodies to desmoglein 1 and 3, and the clinical phenotype of pemphigus vulgaris. $J \mathrm{Am}$ Acad Dermatol. 2003;48(6):976-977. https://doi.org/10.1067/ mjd.2003.438

43. Bağc1 IS, Horváth ON, Ruzicka T, Sárdy M. Bullous pemphigoid. Autoimmun Rev. 2017;16(5):445-455. https://doi.org/10.1016/ j.autrev.2017.03.010

44. Murrell DF, Peña S, Joly P, et al. Diagnosis and management of pemphigus: recommendations of an international panel of experts. J Am Acad Dermatol. 2020;82(3):575-585.e1. https://doi. org/10.1016/j.jaad.2018.02.021

45. Almugairen N, Hospital V, Bedane C, et al. Assessment of the rate of long-term complete remission off therapy in patients with pemphigus treated with different regimens including medium- and high-dose corticosteroids. J Am Acad Dermatol. 2013;69(4):583588. https://doi.org/10.1016/j.jaad.2013.05.016

46. Mentink LF, Mackenzie MW, Tóth GG, et al. Randomized controlled trial of adjuvant oral dexamethasone pulse therapy in pemphigus vulgaris: PEMPULS trial. Arch Dermatol. 2006;142(5):570576. https://doi.org/10.1001/archderm.142.5.570
47. Sharma VK, Gupta V, Bhari N, Singh V. Rituximab as an adjuvant therapy for pemphigus: experience in 61 patients from a single center with long-term follow-up. Int J Dermatol. 2020;59(1):7681. https://doi.org/10.1111/ijd.14546

48. De D, Bishnoi A, Handa S, Mahapatra T, Mahajan R. Effectiveness and safety analysis of rituximab in 146 Indian pemphigus patients: a retrospective single-center review of up to 68 months follow-up. Indian J Dermatol Venereol Leprol. 2020;86(1):39-44. https://doi.org/10.4103/ijdvl.IJDVL_848_17

49. Wang HH, Liu CW, Li YC, Huang YC. Efficacy of rituximab for pemphigus: a systematic review and meta-analysis of different regimens. Acta Derm Venereol. 2015;95(8):928-932. https://doi. org/10.2340/00015555-2116

50. Joly P, Maho-Vaillant M, Prost-Squarcioni C, et al. First-line rituximab combined with short-term prednisone versus prednisone alone for the treatment of pemphigus (Ritux 3): a prospective, multicentre, parallel-group, open-label randomised trial. Lancet. 2017;389(10083):2031-2040. https://doi.org/10.1016/S01406736(17)30070-3

51. Chen DM, Odueyungbo A, Csinady E, et al. Rituximab is an effective treatment in patients with pemphigus vulgaris and demonstrates a steroid-sparing effect. Br J Dermatol. 2020;182(5):11111119. https://doi.org/10.1111/bjd.18482

52. Daneshpazhooh M, Balighi K, Mahmoudi H, et al. Iranian guideline for rituximab therapy in pemphigus patients. Dermatol Ther. 2019;32(5):e13016. https://doi.org/10.1111/dth.13016

53. Albers LN, Liu Y, Bo N, Swerlick RA, Feldman RJ. Developing biomarkers for predicting clinical relapse in pemphigus patients treated with rituximab. J Am Acad Dermatol. 2017;77(6):10741082. https://doi.org/10.1016/j.jaad.2017.07.012

54. Saleh MA. A prospective study comparing patients with early and late relapsing pemphigus treated with rituximab. J Am Acad Dermatol. 2018;79(1):97-103. https://doi.org/10.1016/ j.jaad.2018.01.029

55. Sharma VK, Bhari N, Gupta S, et al. Clinical efficacy of rituximab in the treatment of pemphigus: a retrospective study. Indian J Dermatol Venereol Leprol. 2016;82(4):389-394. https://doi. org/10.4103/0378-6323.174379

56. de Sena Nogueira Maehara L, Huizinga J, Jonkman MF. Rituximab therapy in pemphigus foliaceus: report of 12 cases and review of recent literature. Br J Dermatol. 2015;172(5):1420-1423. https://doi.org/10.1111/bjd.13586

57. Eming R, Sticherling M, Hofmann SC, et al. S2k guidelines for the treatment of pemphigus vulgaris/foliaceus and bullous pemphigoid. J Dtsch Dermatol Ges. 2015;13(8):833-844. https://doi. org/10.1111/ddg.12606

58. Kirtschig G, Middleton P, Bennett C, Murrell DF, Wojnarowska F, Khumalo NP. Interventions for bullous pemphigoid: a summarised Cochrane review. Clin Exp Dermatol. 2011;36(4):449450. https://doi.org/10.1111/j.1365-2230.2011.04104.x

59. Joly P, Roujeau JC, Benichou J, et al. A comparison of oral and topical corticosteroids in patients with bullous pemphigoid. N Engl J Med. 2002;346(5):321-327. https://doi.org/10.1056/ NEJMoa011592

60. Joly P, Roujeau JC, Benichou J, et al. A comparison of two regimens of topical corticosteroids in the treatment of patients with bullous pemphigoid: a multicenter randomized study. J Invest Dermatol. 2009;129(1):1681-1687. https://doi.org/10.1038/ jid.2008.412 
61. Williams HC, Wojnarowska F, Kirtschig G, et al. Doxycycline versus prednisolone as an initial treatment strategy for bullous pemphigoid: a pragmatic, non-inferiority, randomised controlled trial. Lancet. 2017;389(10079):1630-1638. https://doi.org/10.1016/ S0140-6736(17)30560-3

62. Yamagami J. Recent advances in the understanding and treatment of pemphigus and pemphigoid. F1000Res. 2018;7:F1000 Faculty Rev-1360. Published 2018 Aug 30. https://doi.org/10.12688/ f1000research.14474.1

63. Sticherling M, Franke A, Aberer E, et al. An open, multicentre, randomized clinical study in patients with bullous pemphigoid comparing methylprednisolone and azathioprine with methylprednisolone and dapsone. Br J Dermatol. 2017;177(5):12991305. https://doi.org/10.1111/bjd.15649

64. Kremer N, Snast I, Cohen ES, et al. Rituximab and omalizumab for the treatment of bullous pemphigoid: a systematic review of the literature. Am J Clin Dermatol. 2019;20(2):209-216. https:// doi.org/10.1007/s40257-018-0401-6

65. Amber KT, Maglie R, Solimani F, Eming R, Hertl M. Targeted therapies for autoimmune bullous diseases: current status. Drugs. 2018;78(15):1527-1548. https://doi.org/10.1007/s40265-0180976-5

66. Seyed Jafari SM, Gadaldi K, Feldmeyer L, Yawalkar N, Borradori L, Schlapbach C. Effects of omalizumab on FceRI and IgE ex- pression in lesional skin of bullous pemphigoid. Front Immunol. 2019;10:1919. https://doi.org/10.3389/fimmu.2019.01919

67. Bilgic A, Murrell DF. What is novel in the clinical management of pemphigus. Expert Rev Clin Pharmacol. 2019;12(10):973-980. https://doi.org/10.1080/17512433.2019.1670059

68. Langenhan J, Dworschak J, Saschenbrecker S, et al. Specific immunoadsorption of pathogenic autoantibodies in pemphigus requires the entire ectodomains of desmogleins. Exp Dermatol. 2014;23(4):253-259. https://doi.org/10.1111/exd.12355

69. Hofrichter M, Dworschak J, Emtenani S, et al. Immunoadsorption of desmoglein-3-specific IgG abolishes the blister-inducing capacity of pemphigus vulgaris IgG in neonatal mice. Front Immunol. 2018;9:1935. https://doi.org/10.3389/fimmu.2018.01935

70. Ellebrecht CT, Bhoj VG, Nace A, et al. Reengineering chimeric antigen receptor $\mathrm{T}$ cells for targeted therapy of autoimmune disease. Science. 2016;353(6295):179-184. https://doi.org/10.1126/ science.aaf6756

71. Didona D, Maglie R, Eming R, Hertl M. Pemphigus: current and future therapeutic strategies. Front Immunol. 2019;10:1418. https://doi.org/10.3389/fimmu.2019.01418

72. Wannick M, Assmann JC, Vielhauer JF, et al. The immunometabolomic interface receptor hydroxycarboxylic acid receptor 2 mediates the therapeutic effects of dimethyl fumarate in autoantibody-induced skin inflammation. Front Immunol. 2018;9:1890. https://doi.org/10.3389/fimmu.2018.01890 